\title{
Effects of a helium/oxygen mixture on individuals' lung function and metabolic cost during submaximal exercise for participants with obstructive lung diseases
}

\author{
This article was published in the following Dove Press journal: \\ International Journal of COPD \\ 21 September 2015 \\ Number of times this article has been viewed
}

\author{
Sabine Häussermann' \\ Anja Schulze' \\ Ira $\mathrm{M} \mathrm{Katz}{ }^{2,3}$ \\ Andrew R Martin ${ }^{4}$ \\ Christiane Herpich' \\ Theresa Hunger ${ }^{\prime}$ \\ Joëlle Texereau ${ }^{2}$ \\ 'Inamed GmbH, Gauting, Germany; \\ ${ }^{2}$ Medical R\&D, Air Liquide Santé \\ International, Centre de Recherche \\ Paris-Saclay, Les Loges-en-Josas, \\ France; ${ }^{3}$ Department of Mechanical \\ Engineering, Lafayette College, Easton, \\ PA, USA; ${ }^{4}$ Department of Mechanical \\ Engineering, University of Alberta, \\ Edmonton, $\mathrm{AB}$, Canada
}

\begin{abstract}
Background: Helium/oxygen therapies have been studied as a means to reduce the symptoms of obstructive lung diseases with inconclusive results in clinical trials. To better understand this variability in results, an exploratory physiological study was performed comparing the effects of helium/oxygen mixture $(78 \% / 22 \%)$ to that of medical air.

Methods: The gas mixtures were administered to healthy, asthmatic, and chronic obstructive pulmonary disease (COPD) participants, both moderate and severe (6 participants in each disease group, a total of 30); at rest and during submaximal cycling exercise with equivalent work rates. Measurements of ventilatory parameters, forced spirometry, and ergospirometry were obtained.
\end{abstract}

Results: There was no statistical difference in ventilatory and cardiac responses to breathing helium/oxygen during submaximal exercise. For asthmatics, but not for the COPD participants, there was a statistically significant benefit in reduced metabolic cost, determined through measurement of oxygen uptake, for the same exercise work rate. However, the individual data show that there were a mixture of responders and nonresponders to helium/oxygen in all of the groups.

Conclusion: The inconsistent response to helium/oxygen between individuals is perhaps the key drawback to the more effective and widespread use of helium/oxygen to increase exercise capacity and for other therapeutic applications.

Keywords: helium/oxygen, inspiratory capacity, oxygen uptake, COPD, asthma, obstructive airway diseases, exercise, heliox

\section{Introduction}

Obstructive lung diseases such as asthma and chronic obstructive pulmonary disease (COPD) are complex, multifactorial diseases, which result from different pathophysiological conditions. The commonality of airway narrowing results in increased inspiratory and expiratory resistance to flow that induces, among other effects, a greater work of breathing. In turn, increased work of breathing can lead to respiratory muscle fatigue that may contribute to breathlessness and to the development of a life-threatening acute respiratory failure. Furthermore, in spite of the various disease management strategies employed to lessen the obstructions (eg, bronchodilators), the increased work of breathing tends to reduce exercise capacity, leading to negative long-term outcomes. This is especially the case for COPD patients because the obstructions are not reversible. ${ }^{1}$

\footnotetext{
Correspondence: Ira M Katz

Air Liquide Santé International, Medical R\&D, Centre de Recherche Paris-

Saclay, I Chemin de la Porte des Loges, 78350 Les Loges-en-Josas, France Tel +33 I 390765 I I

Email ira.katz@airliquide.com
} 
Helium/oxygen $\left(\mathrm{He} / \mathrm{O}_{2}\right)$ therapies have been studied as a means to reduce the symptoms of obstructive lung diseases, with mixed results. With regard to acute asthma, several clinical studies and case reports have been published to date on the use of $\mathrm{He} / \mathrm{O}_{2}$ mixtures in the management of exacerbations in adults and children. Helium/oxygen mixtures were used according to two fundamentally different therapeutic approaches: first, to lower the work of breathing and thus to relieve respiratory muscle $\operatorname{load}^{2-8}$ and second, as a carrier gas mixture for drug nebulization to improve bronchodilator deposition in the airways. ${ }^{9-11}$ Similar to asthma, inconclusive results have been reported for $\mathrm{He} / \mathrm{O}_{2}$ therapies of COPD, and there have been no definitive major clinical trials that prove efficacy. ${ }^{12-15}$ However, typically clinical trials have used spirometry as the primary measure of disease severity even though it is an unsatisfactory surrogate marker of disease activity, the type of airway lesions, or for distinguishing COPD subphenotypes ${ }^{16}$ thus, it is possible that $\mathrm{He} / \mathrm{O}_{2}$ has not been adequately evaluated.

The mechanisms underlying how $\mathrm{He} / \mathrm{O}_{2}$ breathing could benefit patients with acute or chronic obstructive airway diseases are now better understood from computational, ${ }^{17,18}$ experimental, ${ }^{19,20}$ and clinical approaches. ${ }^{1,21,22} \mathrm{He} / \mathrm{O}_{2}$ decreases airway resistance due to obstructions, but only the component of resistance that is density dependent, ie, either due to turbulence (occurring in upper and large conducting airways) or acceleration/deceleration of gas flow as it passes through airway branching and obstructions (occurring approximately to the tenth lung generation). Furthermore, expiratory airflow limitation can also be positively influenced by breathing $\mathrm{He} / \mathrm{O}_{2}$ because the resistance to exhalation is reduced, reducing operational lung volume. ${ }^{19}$ Conversely, because the viscosity of $\mathrm{He} / \mathrm{O}_{2}$ is slightly greater than those of air or oxygen, ${ }^{17}$ resistance in the straight parts of the very small airways (where the flow is laminar) is greater. Also, the effect of $\mathrm{He} / \mathrm{O}_{2}$ is negligible on the elastic component of the work of breathing, ie, the work required to expand the lung and chest wall. Thus, although in theory, patients with an obstructive airway disease breathing $\mathrm{He} / \mathrm{O}_{2}$ will potentially have decreased airway resistance and reduced work of breathing compared to breathing air or oxygen, $\mathrm{He} / \mathrm{O}_{2}$ will benefit only patients for whom an elevated level of airway resistance is predominantly due to an increase in the densitydependent component.

Pathophysiological effects of $\mathrm{He} / \mathrm{O}_{2}$ mixtures in patients with COPD in a stable state have been investigated in exploratory studies involving small numbers of patients. These studies provide useful information about how $\mathrm{He} / \mathrm{O}_{2}$ mixtures could represent a therapeutic advantage for patients with COPD. For example, several studies concluded that $\mathrm{He} / \mathrm{O}_{2}$ breathing was beneficial during exercise but had no effect on lung mechanics and gas exchange at rest. ${ }^{23-25}$ Palange et $\mathrm{al}^{24}$ and Eves et $\mathrm{al}^{23}$ showed that $\mathrm{He} / \mathrm{O}_{2}$ mixture inhalation while cycling resulted in delayed dynamic hyperinflation and improved respiratory mechanics, which translated into increased maximum ventilatory capacity, better exercise tolerance, and higher intensity level of exercise. Similarly, in a randomized, cross-over, blinded study including 82 COPD patients, Laude et $\mathrm{al}^{26}$ demonstrated that breathing $\mathrm{He} / \mathrm{O}_{2} 72 \% / 28 \%$ or $79 \% / 21 \%$ mixtures increased shuttle walking distance and reduced dyspnoea score and that these positive effects were greater in the most severely obstructed patients.

The influence of disease, and disease severity, on efficacy of $\mathrm{He} / \mathrm{O}_{2}$ is not well understood and contributes to the fact that responders and nonresponders to $\mathrm{He} / \mathrm{O}_{2}$ therapies are not easily identified. ${ }^{27}$ To better understand the variability in results of $\mathrm{He} / \mathrm{O}_{2}$ therapy, an exploratory physiological study was performed. Herein are reported the results of this single site, exploratory, phase I/II, randomized trial comparing the effects of $\mathrm{He} / \mathrm{O}_{2}$ mixture $(78 \% / 22 \%)$. The gases were administered to healthy, asthmatic, and COPD participants, both moderate and severe, as $\mathrm{HeO}_{2}$ efficacy could be affected by the pattern of airway obstructive limitation, at rest and during submaximal cycling exercise. Measurements of ventilatory parameters, forced spirometry, and ergospirometry were obtained. The analysis presented herein is focused on the metabolic cost of exercise, especially in terms of the response of individual participants to exercise while breathing $\mathrm{He} / \mathrm{O}_{2}$. The results of this study may also contribute toward a better overall understanding of how $\mathrm{He} / \mathrm{O}_{2}$ mixtures could be a benefit to patients with obstructive lung diseases depending on the nature of airway remodeling.

\section{Materials and methods Participants}

The main criteria for inclusion were based on the health status of the participant, healthy $(n=6)$, asthmatic $(n=12)$, or diagnosed with COPD $(n=12)$. Healthy volunteers and asthmatics had to be never-smokers or had to have stopped smoking at least 6 months before selection, with a smoking history of less than 10 pack-years. Asthma was to be clinically diagnosed and classified moderate $(n=6)$ or severe persistent $(n=6)$ according to symptoms and lung function in accordance with the Global Initiative for Asthma guidelines. ${ }^{12}$ COPD was to be clinically diagnosed and classified as moderate 
$(n=6)$ or severe $(n=6)$ based on postbronchodilator forced expiratory volume in 1 second $\left(\mathrm{FEV}_{1}\right)$ in accordance with the Global Initiative for Chronic Obstructive Lung Disease guidelines. ${ }^{28}$ All participants were to be outpatients during the study and had to have been free from exacerbation for at least 4 weeks. The study was approved by the local ethics committee (Ethikkommission der Bayrischen Landesärztekammer) and by the BfArM (EudraCT number: 2007-004158-10; ClinicalTrials.gov identifier: NCT00801307).

\section{Study design}

The study was single site, randomized, single blind, and three times cross-over (Figure 1). After having performed baseline spirometry and body plethysmography, participants were assigned for inhalation experiments at rest and during light cycling exercise while breathing helium-oxygen 78\%/22\%, $65 \% / 35 \%$ or medical air (nitrogen/oxygen, $78 \% / 22 \%$ ) in a randomized order. Before the measurements, participants had abstained from bronchodilators for at least 12 hours for long-acting bronchodilators and/or 6 hours for short-acting bronchodilators. In this paper, only $78 \% / 22 \%$ results and analysis are presented to focus on the effects of inhaled helium as opposed to elevated oxygen concentration and because no control data were taken with a $65 \% / 35 \%$ nitrogen/ oxygen, making direct comparisons impossible.

\section{Inhaled gas mixtures}

$\mathrm{He} / \mathrm{O}_{2}$ mixtures were supplied by Air Liquide Deutschland GmbH, (Paris, France) and medical air by Air Liquide Santé
France (Aix-en-Provence, France) in 50 L gas cylinders, with pressure regulators. The initially dry gas mixtures were delivered through a bubble humidifier to a large volume breathing bag. Flow of gas from the cylinders to the breathing bag was adjusted individually for each participant to ensure the bag remained inflated. The breathing bag was connected to a flow sensor (Triple V, Viasys, Höchberg, Germany) and one-way breathing valve (Radiax, Viasys) to minimize leakage and prevent exhaled gas from entering the breathing bag. Participants inhaled gas mixtures from the breathing bag through the flow sensor and one-way valve via a mouthpiece.

\section{Lung function measurements}

Body plethysmography and spirometry were performed in seated position using a Jaeger Masterlab (Viasys). During the inhalation experiments, spirometry and ergometry was performed at rest, after an initial 5 minutes wash-in phase with the gas mixtures in the allocated order, and during cycling using the Jaeger Oxycon Pro (Viasys). Measurements were performed according to the international guidelines and expressed in absolute and percent of predicted for age, sex, and height. ${ }^{29}$

\section{Submaximal exercise protocol: light cycling}

After 5 minutes of rest, each subject was asked to perform 5 minutes of unloaded cycling and then 5 minutes of submaximal cycling exercise with the gas mixtures in the allocated order. The predicted maximum exercise work rate $\left(\mathrm{WR}_{\max }\right)$

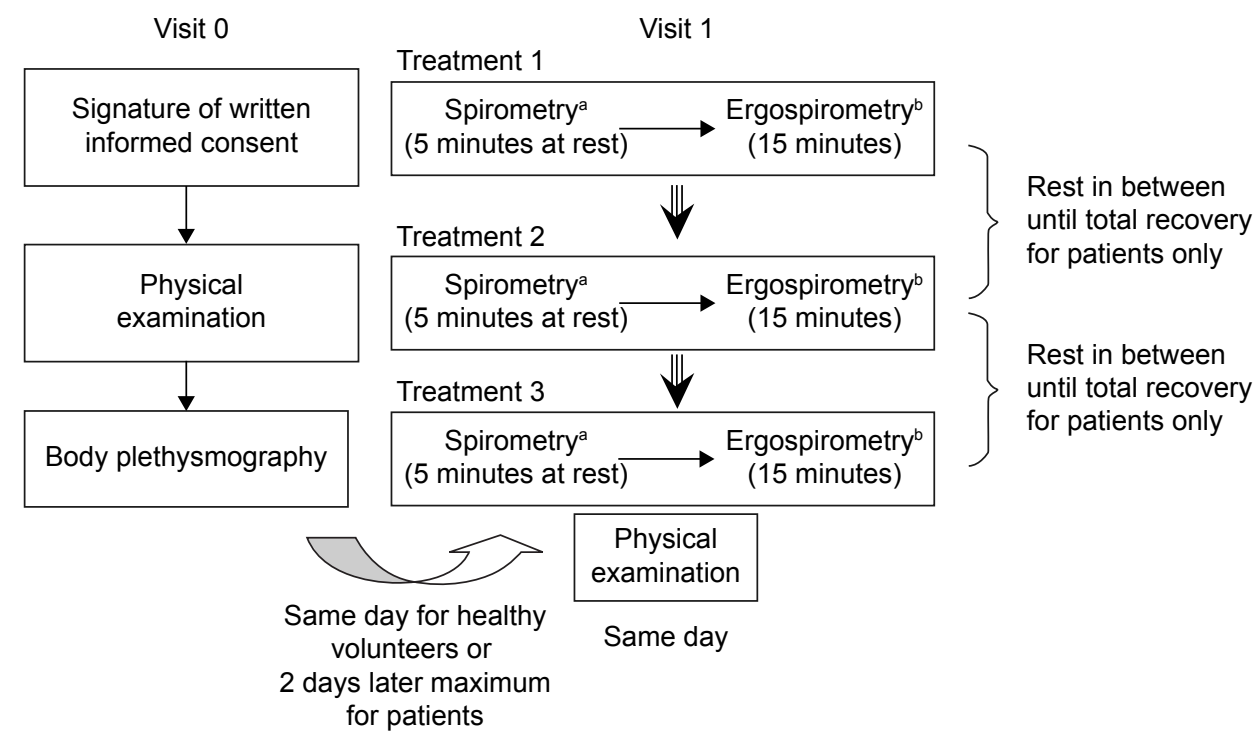

Figure I Study flowchart.

Notes: a $\mathrm{A} 5$-minute initial wash-in for healthy volunteers and patients before performing any evaluation. ${ }^{\mathrm{b}} \mathrm{A} 5$-minute at rest followed by 5 minutes exercise at 0 Watts and 5 minutes individually adjusted, light adjusted cycling exercise. 
in watts (it was not measured) was determined based on a correlation for COPD patients given by Diaz et $\mathrm{al}^{30}$ :

$\mathrm{WR}_{\max }=-7.2+0.43 \mathrm{IC}(\%$ pred $)+0.37\left(\mathrm{FEV}_{1} / \mathrm{FVC}(\%\right.$ pred $\left.)\right)$,

where IC is the inspiratory capacity, $\mathrm{FEV}_{1}$ is the forced expiratory capacity in 1 second, and FVC is the forced vital capacity. The participants were instructed to maintain cycling at 50-60 revolutions per minute to keep the work rate constant during the measurements. Expired gases $\left(\mathrm{V}^{\prime} \mathrm{O}_{2}\right.$, $\mathrm{V}^{\prime} \mathrm{Co}_{2}$ ) and minute ventilation $\left(\mathrm{V}^{\prime} \mathrm{E}\right)$ were measured breathby-breath using the Jaeger Oxycon Pro (Viasys). The Jaeger Oxycon Pro turbine pneumotachograph and gas analyzer were calibrated before each inhalation experiment with the appropriate gas mixture.

\section{Evaluation criteria and statistics}

The analysis presented herein is primarily based on using oxygen uptake $\left(\mathrm{V}^{\prime} \mathrm{O}_{2}\right)$ as an indirect measure of the metabolic cost of submaximal exercise under air or $\mathrm{He} / \mathrm{O}_{2}$ breathing. ${ }^{31}$ Considered first is $\mathrm{V}^{\prime} \mathrm{O}_{2}$ at baseline normalized by an accepted value for average resting oxygen consumption $\left(3.5 \mathrm{~mL} \mathrm{O}_{2} /\right.$ $\mathrm{kg} / \mathrm{min})^{32}$ and $\mathrm{nV}^{\prime} \mathrm{O}_{2}$, calculated to evaluate the status of the participants at rest. Second, the metabolic equivalent (MET) cost of exercise while breathing air or $\mathrm{He} / \mathrm{O}_{2}$ is calculated by dividing the $\mathrm{V}^{\prime} \mathrm{O}_{2}$ at submaximal exercise by the $\mathrm{V}^{\prime} \mathrm{O}_{2}$ at the baseline rest condition. To reduce MET shows that $\mathrm{He} / \mathrm{O}_{2}$ is benefiting the subject. The third measure is $\mathrm{V}_{\mathrm{E}}^{\prime} / \mathrm{V}^{\prime} \mathrm{O}_{2}$, which we interpret as a measure of the efficiency of breathing; this ratio represents unit volume of gas delivered to the lungs per unit oxygen consumed. Recognizing that reducing the resistance to flow could be a significant part of the overall energy needs of an obstructed patient during exercise, ${ }^{17}$ to increase this ratio going from air to $\mathrm{He} / \mathrm{O}_{2}$, with the exercise being the same, indicates that the change in gas mixture benefits the patient. ${ }^{33}$

Data are reported as means with the 95\% confidence interval. Statistical significance was set at $P \leq 0.05$. All data collected were tabulated descriptively by study disease and severity as well as by study disease only. On the per protocol data set, comparison of the measurements at rest and during exercise while breathing each gas mixture, were made using the Dunnett's test following a parametric analysis of variance model.

\section{Results}

\section{Subject characteristics}

Thirty-five adults were included in the study after having provided written informed consent. Thirty (6 healthy participants, 12 stable moderate to severe persistent asthmatics, 12 stable moderate to severe COPD participants) completed the study. Demographic data, baseline lung function, and pulse oximetry parameters are presented for each study group in Table 1. For the asthmatics, $57 \%(n=4)$ experienced symptoms more than once a week, and $100 \%(n=7)$ of the severe persistent and $71 \%(n=5)$ of the moderate persistent regularly used rescue short-acting $\beta 2$ agonists. Among participants with COPD, 58\% (moderate $n=3$, severe $n=4$ ) had frequent cough, $75 \%$ (moderate $n=5$, severe $n=4$ ) frequent

Table I Baseline characteristics, pulmonary function tests at rest, and pulse oximetry breathing air of the study groups

\begin{tabular}{|c|c|c|c|c|c|}
\hline & $\begin{array}{l}\text { Healthy } \\
\text { volunteers }\end{array}$ & $\begin{array}{l}\text { Moderate persistent } \\
\text { asthmatics }\end{array}$ & $\begin{array}{l}\text { Severe persistent } \\
\text { asthmatics }\end{array}$ & $\begin{array}{l}\text { Moderate COPD } \\
\text { participants }\end{array}$ & $\begin{array}{l}\text { Severe COPD } \\
\text { participants }\end{array}$ \\
\hline $\operatorname{Sex} M / F(n)$ & $3 / 3$ & $3 / 3$ & $1 / 5$ & $4 / 2$ & $6 / 0$ \\
\hline Age (year) & $32(6.9)$ & $42(11.1)$ & $64(7.8)$ & $66(4.6)$ & $67(7.4)$ \\
\hline $\mathrm{BMI}\left(\mathrm{kg} / \mathrm{m}^{2}\right)$ & $21.5(1.9)$ & $26.1(5.0)$ & $25.6(1.3)$ & $23.5(4.3)$ & $24.7(3.0)$ \\
\hline $\mathrm{FEV}_{1} / \mathrm{FVC}(\%)$ & $80(4)$ & $63(5)$ & $47(8)$ & $52(9)$ & $40(8)$ \\
\hline $\mathrm{FEV}_{1}(\mathrm{~L})$ & $4.05(0.91)$ & $2.66(0.68)$ & $1.29(0.20)$ & $1.82(0.52)$ & $1.29(0.25)$ \\
\hline $\mathrm{FEV}_{\mathrm{I}}$ (\%pred) & $105(\mathrm{II})$ & $76(5)$ & $54(7)$ & $66(11)$ & $42(5)$ \\
\hline IC (L) & $3.4 I(0.87)$ & $3.29(0.98)$ & $2.44(0.50)$ & $2.82(0.61)$ & $2.35(0.43)$ \\
\hline IC (\%pred) & 105 (13) & $107(16)$ & $110(17)$ & $110(26)$ & $77(12)$ \\
\hline RV/TLC (\%) & $27.0(3.9)$ & $37.5(9.4)$ & $54.0(4.7)$ & $49.8(6.9)$ & $56.5(7.9)$ \\
\hline $\mathrm{SpO}_{2}(\%)$ & $98(0.5)$ & $98(0.8)$ & $95(\mathrm{I} .5)$ & $96(1.6)$ & $95(2.4)$ \\
\hline Symptoms > I/week & NA & 3 & 2 & NA & NA \\
\hline Regular use of $\beta 2$ agonists & NA & 5 & 6 & NA & NA \\
\hline Frequent cough & NA & NA & NA & 3 & 4 \\
\hline Frequent expectoration & NA & NA & NA & 5 & 4 \\
\hline Breathlessness score $\geq 3$ & NA & NA & NA & I & 3 \\
\hline Current smokers & NA & NA & NA & 6 & 4 \\
\hline
\end{tabular}

Notes: Data are provided as mean (standard deviation). Grade of breathlessness $\geq 3$ is according to the Modified Medical Research Council Dyspnea Scale.

Abbreviations: BMI, body mass index; F, female; FEV , forced expiratory volume in I second; FVC, forced vital capacity; IC, inspiratory capacity; M, male; NA, not applicable; $\mathrm{RV}$, residual volume; $\mathrm{SpO}_{2}, \mathrm{O}_{2}$ saturation measured at fingertip; TLC, total lung capacity; \%pred, percent predicted. 
expectoration, $33 \%$ (moderate $n=1$, severe $n=3$ ) had a grade of breathlessness $\geq 3$ according to the Modified MRC Dyspnea Scale, and 9 were current smokers. Data provided in Table 1 are not only for the three study groups, healthy, asthmatics, and COPD participants, but are also broken down by severity of disease where this subcategorization is significant, and for individual results the severity will be considered.

\section{Results per study group \\ Effect of $\mathrm{He} / \mathrm{O}_{2}$ breathing on lung function parameters}

At rest, the nonsignificant increases in $\mathrm{FEV}_{1}$ were greater with $\mathrm{He} / \mathrm{O}_{2}$ than that with air (absolute differences were of $+0.23 \mathrm{~L}, 95 \% \mathrm{CI}[-0.90$ to 1.35$]$ for healthy volunteers, $+0.20 \mathrm{~L}, 95 \%$ CI [ -0.35 to 0.75$]$ for asthmatics, and $+0.14 \mathrm{~L}, 95 \% \mathrm{CI}$ [ -0.22 to 0.49$]$ for participants with COPD) ( $P=0.84,0.61$, and 0.58 , respectively).

Measurements of tidal volume $\left(\mathrm{V}_{\mathrm{T}}\right)$ were not significantly different statistically between air and $\mathrm{He} / \mathrm{O}_{2}$ for the healthy, asthmatic, and COPD study groups at rest or during exercise. The difference was statistically significant only for the subgroup of severe COPD participants at rest $(-230 \mathrm{~mL}, 95 \%$ CI $[-440$ to -10$], P=0.04$ ).

Differences in inspiratory capacity measured at rest while breathing $\mathrm{He} / \mathrm{O}_{2}$ compared to those measured with air were not statistically significant, whatever the study group considered: absolute differences were of $-140 \mathrm{~mL}, 95 \% \mathrm{CI}$ $[-0.93$ to $0.65, P=0.87]$ in healthy volunteers, $-150 \mathrm{~mL}, 95 \%$ CI $[-0.92$ to $0.61, P=0.85]$ in asthmatics, and $-360 \mathrm{~mL}, 95 \%$ CI $[-0.98$ to $0.25, P=0.30]$ in participants with COPD. They were also comparable during exercise.

\section{Effect of $\mathrm{He} / \mathrm{O}_{2}$ breathing on exercise test parameters}

Comparisons of selected ventilatory and cardiac parameters measured while breathing $\mathrm{He} / \mathrm{O}_{2} 78 \% / 22 \%$ and air during constant calibrated cycling shows that the differences were small and not statistically significant (Table 2).

For a comparable work rate, oxygen uptake tended to be lower while breathing $\mathrm{He} / \mathrm{O}_{2}$ compared to air in all study groups (absolute differences were of $-321 \mathrm{~mL} / \mathrm{min}, 95 \% \mathrm{CI}$ $[-801$ to +160$]$ in healthy volunteers, $-212 \mathrm{~mL} / \mathrm{min}, 95 \%$ CI [ -376 to -49$]$ in asthmatics, and $-59 \mathrm{~mL} / \mathrm{min}, 95 \% \mathrm{CI}$ $[-236$ to +117$]$ in participants with COPD), but the differences were statistically significant only for the moderate and severe asthmatics (Table 2). The decrease in oxygen uptake while breathing $\mathrm{He} / \mathrm{O}_{2}$ during the submaximal exercise was not associated with a significant decrease in minute ventilation. The same observation was made for $\mathrm{V}^{\prime} \mathrm{Co}_{2}$.

Figure 2 shows the change in $\mathrm{nV}^{\prime} \mathrm{O}_{2}$ while inhaling each gas mixture for each group. The average values indicate that the healthy and unchallenged asthmatics have near normal

Table 2 Physiological response parameters during constant work rate exercise for the different study groups and the two gas mixtures $\left(\mathrm{He} / \mathrm{O}_{2} 78 \% / 22 \%\right.$ and Medical air)

\begin{tabular}{|c|c|c|c|c|c|}
\hline & $\begin{array}{l}\text { Healthy } \\
\text { volunteers }(\mathrm{N}=6)\end{array}$ & $\begin{array}{l}\text { Moderate persistent } \\
\text { asthmatics }(\mathrm{N}=6)\end{array}$ & $\begin{array}{l}\text { Severe persistent } \\
\text { asthmatics }(\mathrm{N}=6)\end{array}$ & $\begin{array}{l}\text { Moderate COPD } \\
\text { participants }(\mathrm{N}=6)\end{array}$ & $\begin{array}{l}\text { Severe COPD } \\
\text { participants }(\mathrm{N}=6)\end{array}$ \\
\hline$W_{R_{\max }}$ (pred) & $67(6.1)$ & $62(6.4)$ & $60(11.6)$ & $57(6.8)$ & $4 \mid(3.3)$ \\
\hline WR (air), Watts & $104(25)$ & $6 I(2 I)$ & $26(8)$ & $35(11)$ & $26(9)$ \\
\hline WR $\left(\mathrm{He} / \mathrm{O}_{2}\right)$, Watts & $110(2 \mathrm{I})$ & $68(24)$ & $29(9)$ & $40(15)$ & $28(8)$ \\
\hline \multicolumn{6}{|l|}{ Metabolic } \\
\hline$V^{\prime} \mathrm{O}_{2}$ (air), mL/min & $1,524(306)$ & $1,193(213)$ & $799(150)$ & $867(187)$ & $886(159)$ \\
\hline$V_{\mathrm{O}_{2}}^{\prime}\left(\mathrm{He} / \mathrm{O}_{2}\right), \mathrm{mL} / \mathrm{min}$ & $\mathrm{I}, 204(392)$ & $922(279) * *$ & $645(106)^{* *}$ & $800(248)$ & $835(219)$ \\
\hline$V^{\prime} \mathrm{co}_{2}($ Air) $), \mathrm{mL} / \mathrm{min}$ & $I, 44 \mid(4 I 2)$ & I,062 (223) & $699(157)$ & $785(184)$ & 745 (I32) \\
\hline$V^{\prime} \mathrm{CO}_{2}\left(\mathrm{He} / \mathrm{O}_{2}\right), \mathrm{mL} / \mathrm{min}$ & $1,014(333)$ & $810(226) * *$ & $499(98)^{* *}$ & $683(175)$ & $628(152)$ \\
\hline \multicolumn{6}{|l|}{ Cardiovascular } \\
\hline HR (Air), beats/min & $135(20)$ & $110(10)$ & $92(12)$ & $104(12)$ & $106(20)$ \\
\hline $\mathrm{HR}\left(\mathrm{He} / \mathrm{O}_{2}\right)$, beats/min & $143(16)$ & $109(8)$ & $91(13)$ & $104(I I)$ & $104(16)$ \\
\hline \multicolumn{6}{|l|}{ Ventilatory } \\
\hline RR (Air), breaths/min & $18(3)$ & $21(4)$ & $21(5)$ & $27(4)$ & $25(5)$ \\
\hline $\mathrm{RR}\left(\mathrm{He} / \mathrm{O}_{2}\right)$, breaths/min & $19(4)$ & $22(4)$ & $20(8)$ & $28(5)$ & $26(4)$ \\
\hline$V_{E}^{\prime}($ Air $), L / m i n$ & $8.0(1.4)$ & $6.0(1.5)$ & $4.8(0.8)$ & $6.7(2.1)$ & $6.0(1.1)$ \\
\hline$V_{E}^{\prime}\left(\mathrm{He} / \mathrm{O}_{2}\right), \mathrm{L} / \mathrm{min}$ & $7.5(1.7)$ & $5.5(1.4)$ & $4.1(0.5)$ & $6.2(1.9)$ & $5.5(0.9)$ \\
\hline $\mathrm{SpO}_{2}$ (Air), \% & $95(1)$ & $96(1)$ & $97(1)$ & $95(1)$ & $96(2)$ \\
\hline $\mathrm{SpO}_{2}\left(\mathrm{He} / \mathrm{O}_{2}\right), \%$ & $96(1)$ & $97(\mathrm{I})$ & $97(I)$ & $96(I)$ & $95(4)$ \\
\hline
\end{tabular}

Notes: Data are provided as mean (standard deviation). ${ }^{*} * \mathrm{P}<0.05$ as compared to the same variable measured with air.

Abbreviations: WR, work rate; $\mathrm{WR}_{\max }$ (pred), maximum work rate predicted; $\mathrm{HR}$, heart rate; RR, respiratory rate; $\mathrm{SPO}_{2}, \mathrm{O}_{2}$ saturation measured at fingertip; $V_{E}^{\prime}$, minute ventilation; $V^{\prime} \mathrm{O}_{2}$, oxygen uptake; $V^{\prime} \mathrm{CO}_{2}, \mathrm{CO}_{2}$ release; min, minute. 


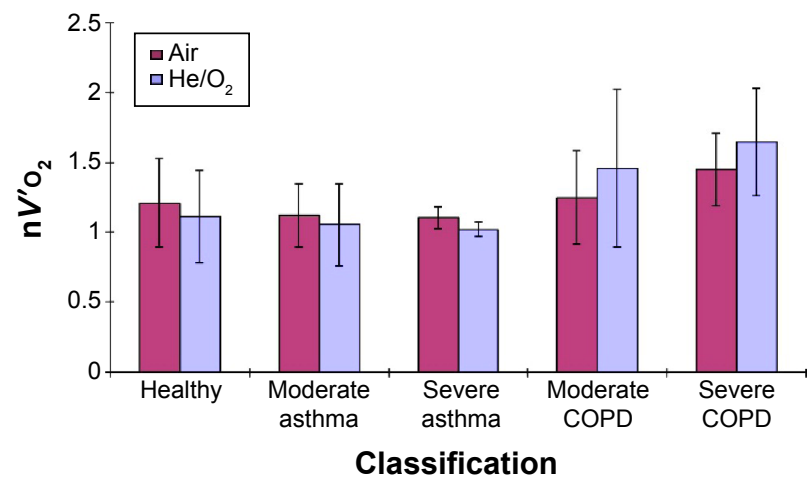

Figure 2 Average of normalized oxygen uptake $n V^{\prime} \mathrm{O}_{2}=V_{\mathrm{O}_{2}}^{\prime} /(3.5 \mathrm{ml} / \mathrm{kg} / \mathrm{min} \times$ weight $\mathrm{kg}$ ) at rest while breathing air or $\mathrm{He} / \mathrm{O}_{2}$ mixture for the healthy, asthmatic, and COPD groups.

Note: The error bars represent standard deviation.

Abbreviations: COPD, chronic obstructive pulmonary disease; $\mathrm{V}^{\prime} \mathrm{O}_{2}$, oxygen uptake.

values (ie, 1 at rest). The COPD participants have elevated $\mathrm{nV}^{\prime} \mathrm{O}_{2}$, indicating they might have difficulty doing everyday activities since this ratio is a measure for exercise capacity. ${ }^{33}$ It is important to point out that for the COPD participants the average response to $\mathrm{He} / \mathrm{O}_{2}$ at rest is negative in terms of metabolic cost in that the $\mathrm{nV}^{\prime} \mathrm{O}_{2}$ increased. In Figure 3, the average MET values for submaximal exercise are shown; now note that for all groups there is some benefit due to $\mathrm{He} / \mathrm{O}_{2}$. The work rate of the exercise ranges from the equivalent of very heavy housework for the healthy participants to very light housework for the severe participants (Table 2). ${ }^{32}$

\section{Individual results}

Effect of $\mathrm{He} / \mathrm{O}_{2}$ on the metabolic cost for individuals Plots showing the change in $\mathrm{nV}^{\prime} \mathrm{O}_{2}$ and MET while inhaling each gas mixture at rest and at submaximal exercise for each subject are shown in Figures 4 and 5, respectively. Plots

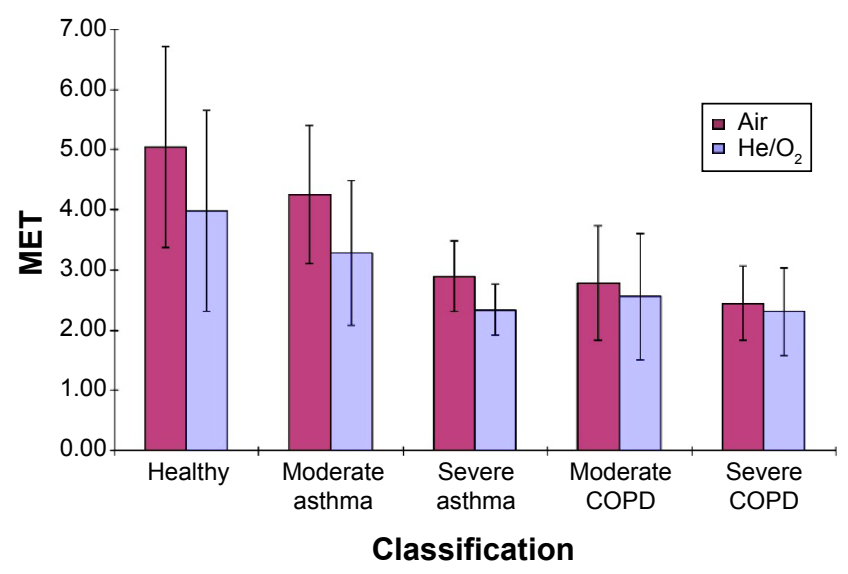

Figure 3 Average MET after submaximal exercise for each subject group. Note: The error bars represent standard deviation.

Abbreviation: MET, metabolic equivalent. showing the change of $\mathrm{V}_{\mathrm{E}}^{\prime} / \mathrm{V}^{\prime} \mathrm{O}_{2}$ during exercise for each subject are shown in Figure 6.

Figure 7 shows the percent change in the metabolic cost of breathing in terms of $\mathrm{V}_{\mathrm{E}}^{\prime} / \mathrm{V}^{\prime} \mathrm{O}_{2}$ going from air to $\mathrm{He} / \mathrm{O}_{2}$ for each subject and categorized by subject group plotted as a function of inspiratory capacity percent predicted (IC\%). A positive change indicates a benefit to breathing the $\mathrm{He} / \mathrm{O}_{2}$ mixture. The ratio $\mathrm{V}_{\mathrm{E}}^{\prime} / \mathrm{V}^{\prime} \mathrm{O}_{2}$ represents unit volume of gas delivered to the lungs per unit energy expended. Thus, to increase this ratio going from air to helium/oxygen, with the exercise being the same, indicates that the change in gas mixture benefits the patient. Furthermore, while the effect of $\mathrm{He} / \mathrm{O}_{2}$ has no direct effect on the elastic component of the work of breathing (ie, the work required to expand the lung and chest wall) reduced operational lung volume due to lower resistance during exhalation could in turn reduce the work required for inhalation.

\section{Discussion}

In this study, $\mathrm{He} / \mathrm{O}_{2}$ mixtures and medical air were administered to healthy, asthmatic, and COPD participants at rest and during submaximal cycling exercise. Consistent with other exercise studies, ${ }^{24}$ there was no statistical difference in ventilatory and cardiac responses to breathing $\mathrm{He} / \mathrm{O}_{2}$ during exercise. For asthmatics, there was a statistical benefit in reduced metabolic cost for the same exercise work rate, but not for the COPD participants. However, the individual data as shown in Figures 5 and 6 indicate that there were both responders and nonresponders to $\mathrm{He} /$ $\mathrm{O}_{2}$ in all of the groups similar to other $\mathrm{He} / \mathrm{O}_{2}$-based respiratory therapies. ${ }^{14,34}$ For example, there was an increase in metabolic cost from $+60 \%$ to $-20 \%$ change compared to values measured for air. These data suggest that the clinical drawback of inconsistent response is a key limitation to the effective and widespread use of $\mathrm{He} / \mathrm{O}_{2}$ to increase exercise capacity, and this may be the case for other therapeutic applications as well. Thus, these results reinforce the practical importance of the prediction of response to $\mathrm{He} / \mathrm{O}_{2}$ therapy noted by others. ${ }^{34,35}$

This was an exploratory study such that each subgroup of participants was small $(n=6)$, but the presence of responders and nonresponders suggests that even if the number of subjects were increased substantially, statistically significant results might be elusive. This particular point was the motivation to emphasize individual results in this paper. Furthermore, we believe that the search for the respiratory/mechanical biomarkers that would predict response is a key to expanding the successful use of $\mathrm{He} / \mathrm{O}_{2}$ therapies. 

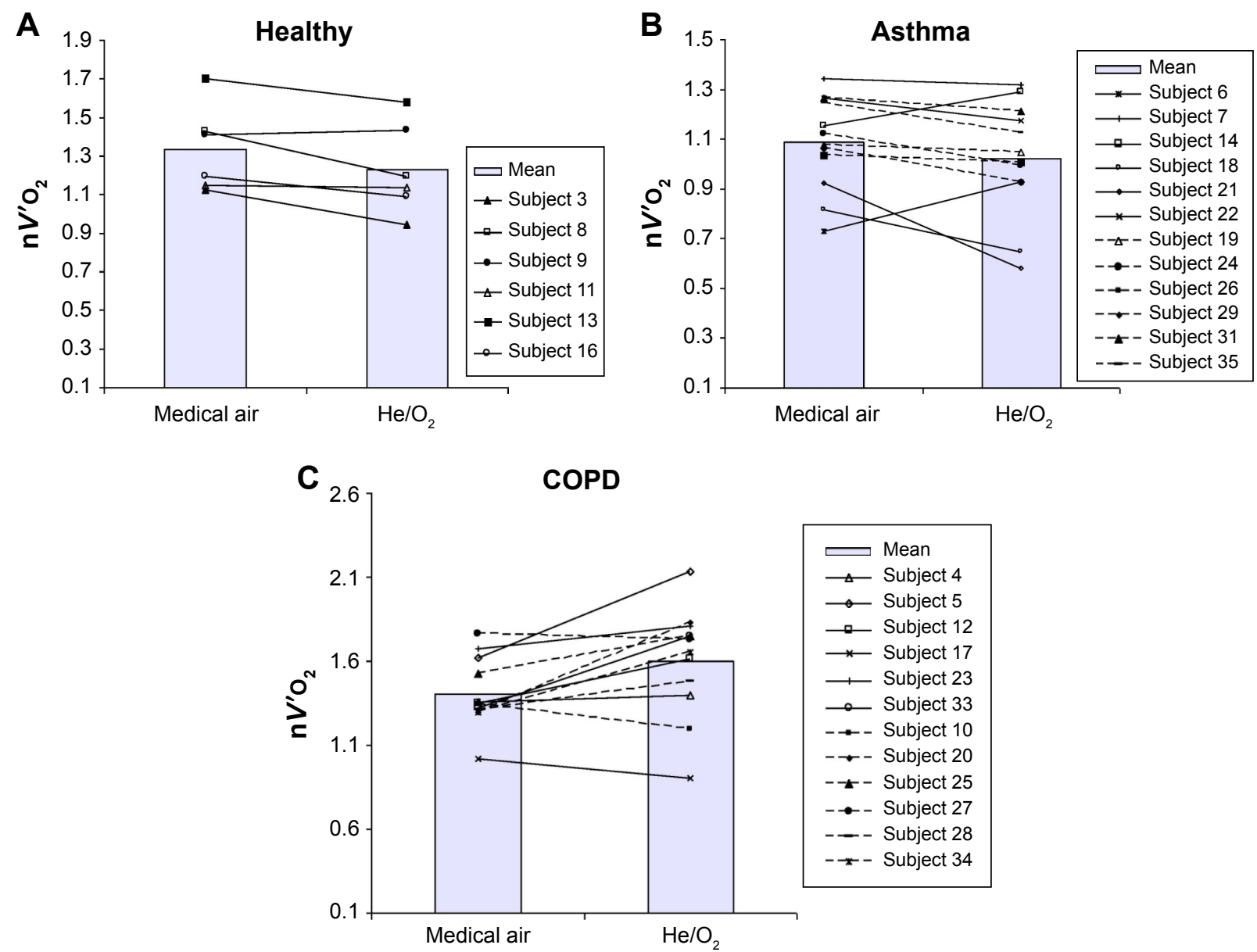

Figure 4 Individual changes in normalized oxygen uptake $\mathrm{nV}^{\prime} \mathrm{O}_{2}=\mathrm{V}_{\mathrm{O}_{2}} /(3.5 \mathrm{~mL} / \mathrm{kg} / \mathrm{min} \times$ weight $\mathrm{kg})$ at rest while breathing air or He/O $\mathrm{mixture}$.

Notes: For the subject groups solid and dashed lines are for moderate and severe cases, respectively. The bars represent the mean values. There were only 30 participants in total who completed the study, but subject numbers were assigned to other initiated patients who later dropped out while the original subject numbers are retained.

Abbreviations: $\mathrm{COPD}$, chronic obstructive pulmonary disease; $\mathrm{V}^{\prime} \mathrm{O}_{2}$, oxygen uptake.

However, as discussed below, the familiar pathological descriptors (eg, asthma and COPD and their severity) and quantitative measures of pathology $\left(\mathrm{eg}, \mathrm{FEV}_{1}\right)$ are not adequate predictors of response. Noting the difficulty in predicting responders to $\mathrm{He} / \mathrm{O}_{2}$ therapy, the underlying causes are probably related to the interaction of gas flow rate and the location and severity of obstructions. Thus, especially for COPD, response can be as varied as is the nature of this complex syndrome.

Of the various baseline lung function measurements taken, only IC\% predicted showed a correlation to metabolic cost; and only for the healthy and COPD participants, but not at all for asthmatics. The correlations and the coefficients are shown in Figure 7. This result is in agreement with that of Puente-Maestu et a ${ }^{36}$ in that there is a good correlation between the resting IC $\%$ predicted and the oxygen uptake during exercise for COPD participants. Regarding the delineation of responders and nonresponders to $\mathrm{He} / \mathrm{O}_{2}$ therapy, two points can be made. First, the fact that there was a fairly good correlation of IC\% predicted with the metabolic cost of exercise for healthy volunteers and COPD participants suggests that it might be used as the predictor response. This potential is somewhat supported by D'Angelo et a $l^{34}$ who found a strong correlation with IC\% predicted for the presence of tidal expiratory flow limitation. A second point to be made is that the exercise/ergospirometry tests performed for this study could serve as a predictor for responders as shown in Figure 7, with the significant but surprising caveat that $\mathrm{He} / \mathrm{O}_{2}$ therapy performs better with the increasing $\mathrm{IC} \%$ predicted, ie, for the less severe COPD.

An additional potential benefit of breathing $\mathrm{He} / \mathrm{O}_{2}$ during exercise is the reduction of expiratory flow limitation and decreased dynamic hyperinflation. ${ }^{34,35}$ However here IC did not improve between rest and exercise as an indicator that hyperinflation had decreased. A potential explanation for this lack of response was the relative severity of disease of the participants or severity of hyperinflation in terms of hyperinflation. Only the severe COPD participants had IC\% 

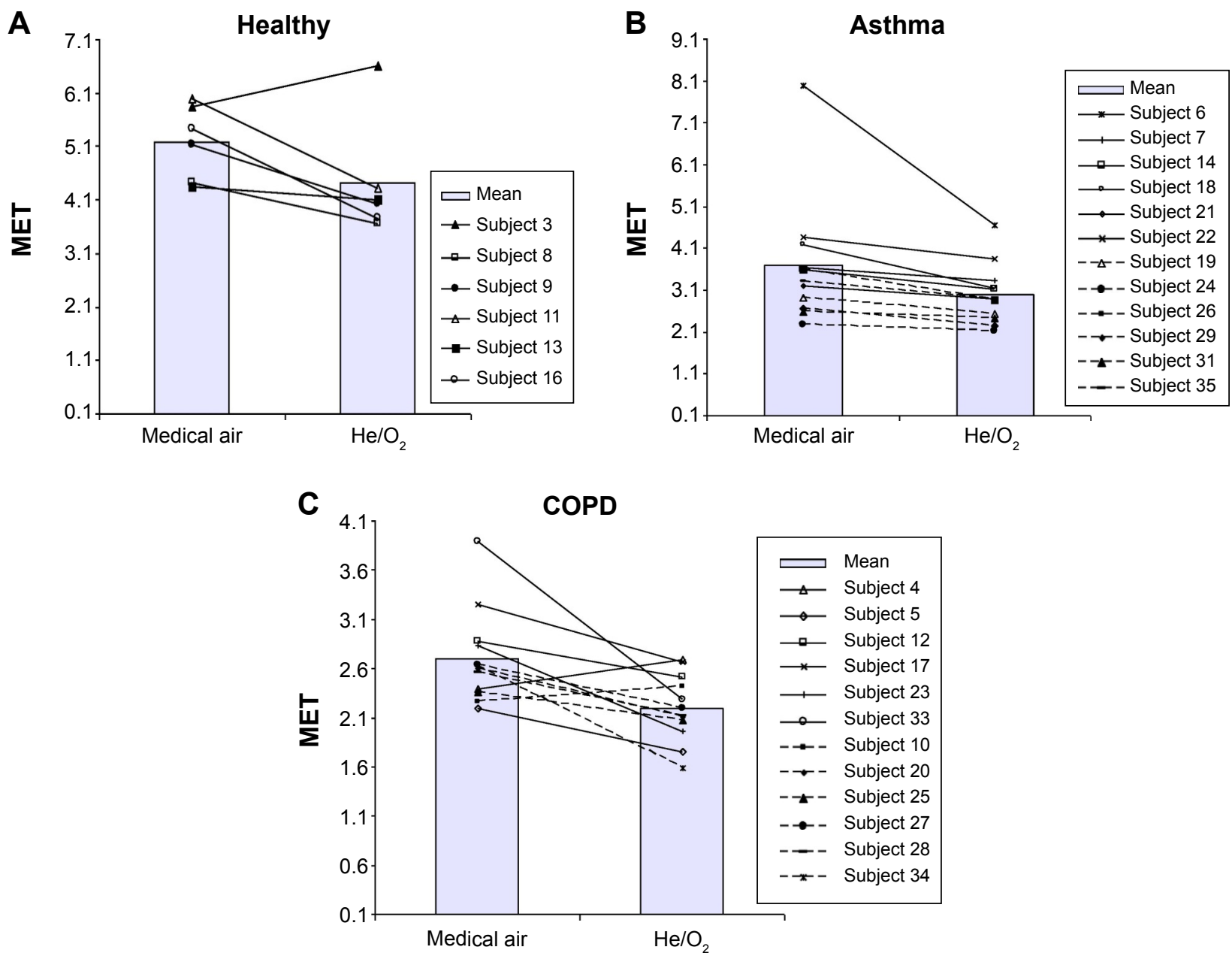

Figure 5 Individual changes in MET after submaximal exercise while breathing air or $\mathrm{He}_{2} \mathrm{O}_{2}$ for the (A) healthy, (B) asthmatic, and (C) COPD groups.

Notes: MET is based on $V^{\prime} \mathrm{O}_{2}$ measure for each subject at rest. For the subject groups, solid and dashed lines are for moderate and severe cases, respectively. The bars represent the mean values. There were only 30 participants in total who completed the study, but subject numbers were assigned to other initiated patients who later dropped out while the original subject numbers are retained.

Abbreviations: MET, metabolic equivalent; COPD, chronic obstructive pulmonary disease; $\mathrm{V}^{\prime} \mathrm{O}_{2}$, oxygen uptake.

predicted less than $100 \%$, and only three of those individuals had values less than $80 \%$. For more nuanced arguments on the effects of $\mathrm{He} / \mathrm{O}_{2}$ on tidal expiratory flow limitation and IC, see D'Angelo et al. ${ }^{34}$

Three mechanisms have been proposed as the major limitation to exercise performance in COPD: inadequate energy supply to the respiratory and locomotor muscles, lower limb muscle dysfunction, or dynamic hyperinflation. Recent studies of physiological response to $\mathrm{He} / \mathrm{O}_{2}$ and exercise for COPD participants have provided interesting results on whether or not the gas mixture facilitates redistribution of blood flow to the lower limbs. ${ }^{1,22}$ The study presented herein does not add to this discussion, but seems to point to energy needed by the respiratory muscles during submaximal exercise with little hyperinflation.

In this study, the technical details of gas delivery and measurement were scrutinized (eg, all devices were calibrated with $\left.\mathrm{He} / \mathrm{O}_{2}\right)$. In spite of this care, measurement uncertainty or infiltration of ambient air into the $\mathrm{He} / \mathrm{O}_{2}$ at the patient interface could have compromised the results. This is an inherent limitation when using equipment not specifically designed for use with a particular gas. Clearly, another limiting factor in this exploratory study is the small number of subjects. As such, more selective inclusion of subjects might have yielded greater insight into the reason for nonresponse to $\mathrm{He} / \mathrm{O}_{2}$. For example, three-dimensional reconstruction of the airways based on high-resolution computed tomography X-ray has been shown to provide evidence of lung remodeling that could be correlated to response..$^{35}$ Furthermore, patients who were unlikely to benefit from $\mathrm{He} / \mathrm{O}_{2}$ because they were exercise limited due to leg muscle fatigue rather than ventilatory limitations could potentially have been excluded based on the absence of leg discomfort/low leg discomfort Borg scores at the end of medical air exercise, etc. Finally, note that while the goal was to have 

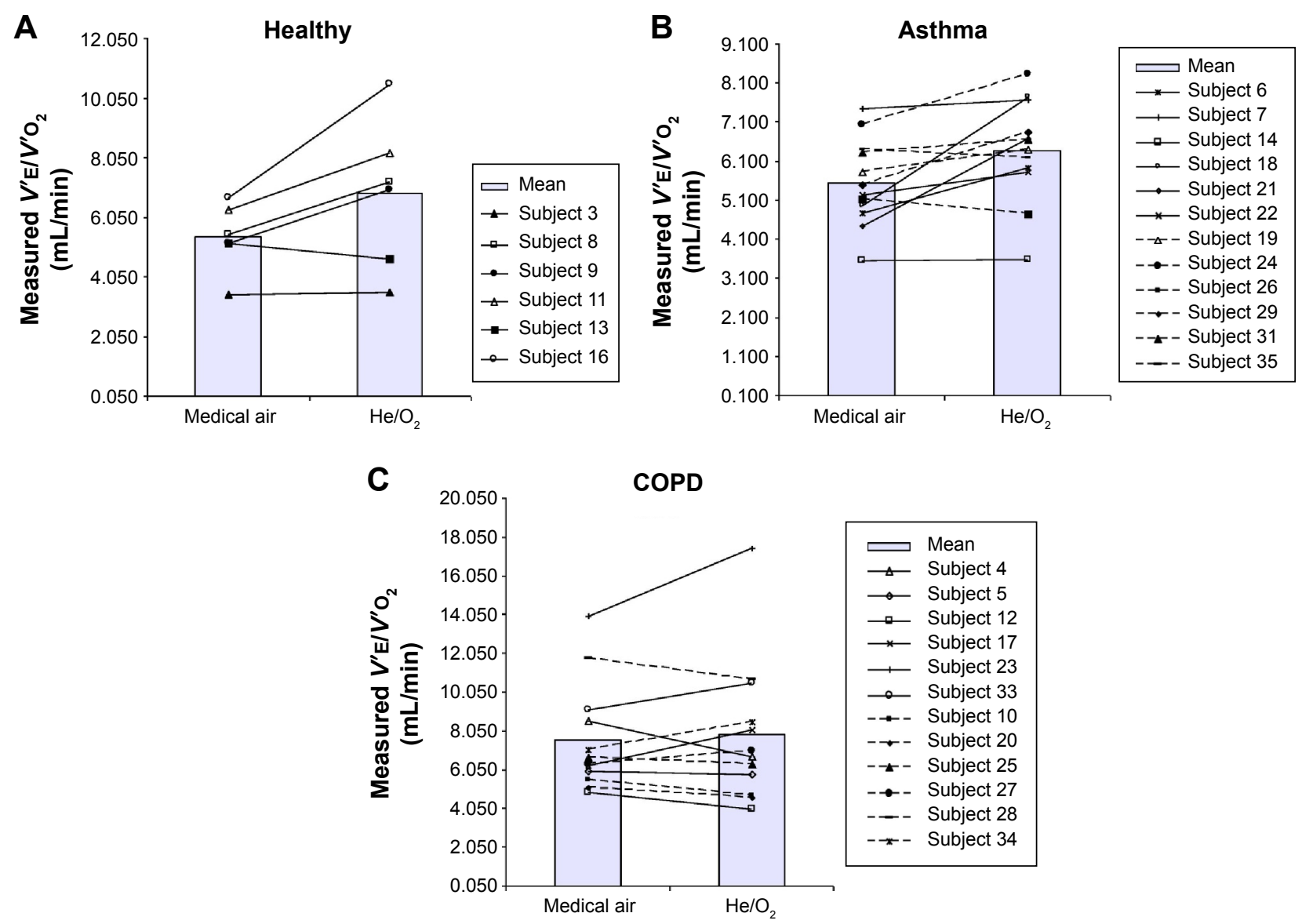

Figure 6 Individual changes in metabolic cost per unit volume of oxygen inspired after submaximal exercise breathing air and $\mathrm{He} / \mathrm{O}_{2}$ mixtures as measured by minute ventilation divided by oxygen uptake $\left(V_{E}^{\prime} / V^{\prime} \mathrm{O}_{2}\right)$ for the $(\mathbf{A})$ healthy, $(\mathbf{B})$ asthmatic, and $(\mathbf{C})$ COPD groups.

Notes: For the subject groups, solid and dashed lines are for moderate and severe cases, respectively. The bars represent the mean values. There were only 30 participants in total who completed the study, but subject numbers were assigned to other initiated patients who later dropped out while the original subject numbers are retained. Abbreviations: COPD, chronic obstructive pulmonary disease; min, minute; $\mathrm{V}^{\prime} \mathrm{O}_{2}$, oxygen uptake.

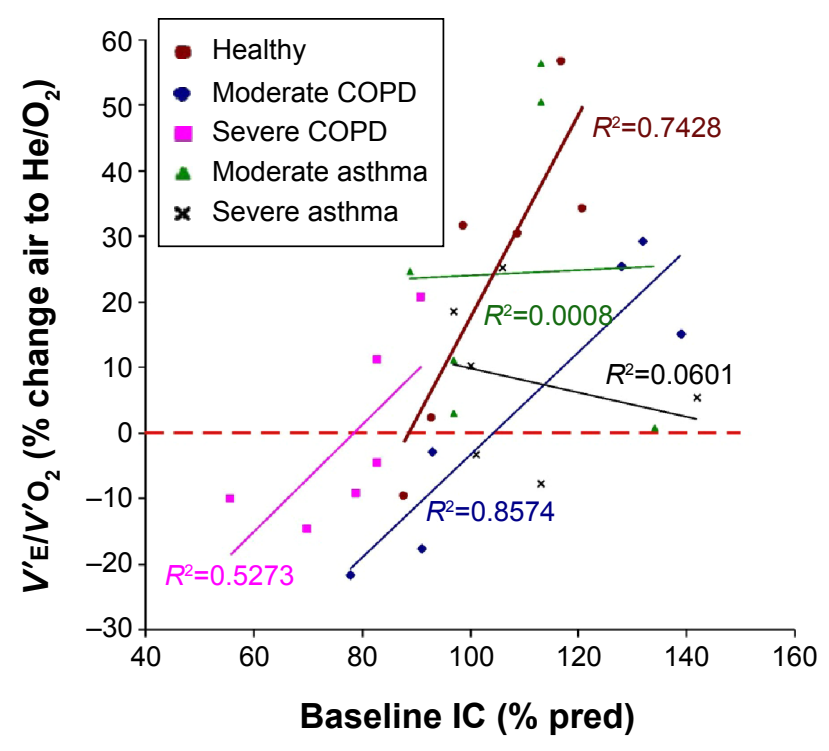

Figure 7 The change in metabolic cost of breathing from air to $\mathrm{He} / \mathrm{O}_{2}$ for each subject and categorized by subject group plotted as a function of IC\% predicted. Note: The dashed line at 0 is the indicator of no benefit.

Abbreviations: COPD, chronic obstructive pulmonary disease; IC\%, inspiratory capacity percent. a consistent level of submaximal exercise across the groups, this was not achieved according to the maximum exercise predicted values listed in Table 2; however, it should be recognized that this correlation was developed for COPD patients. Thus, the actual relative level of exercise is not known.

As mentioned previously, measurements were also performed with $65 \% / 35 \% \mathrm{He} / \mathrm{O}_{2}$ mixture; however, in this paper, these results have not been presented because no data were taken with a $65 \% / 35 \%$ nitrogen/oxygen control, making direct comparisons impossible. However, it should be noted that because supplemental oxygen has been shown to increase exercise tolerance for hypoxemic COPD patients at rest, this mixture should be considered in more depth as an auxiliary to exercise therapy. ${ }^{37}$

\section{Conclusion}

This paper has presented the results of a study where healthy, asthmatic, and COPD participants breathed air and $\mathrm{He} / \mathrm{O}_{2}$ 
$78 \% / 22 \%$ mixture at rest and during submaximal cycling exercise. On average, there is no statistically significant benefit to breathing $\mathrm{He} / \mathrm{O}_{2}$, but the individual responses show that some participants will have an important increase in exercise capacity. Furthermore, IC\% predicted showed promise as a predictor for response to $\mathrm{He} / \mathrm{O}_{2}$ therapy for COPD participants.

\section{Acknowledgment}

This study was funded by Air Liquide.

\section{Disclosure}

The authors report no conflicts of interest in this work.

\section{References}

1. Chiappa GR, Queiroga F Jr, Meda E, et al. Heliox improves oxygen delivery and utilization during dynamic exercise in patients with chronic obstructive pulmonary disease. Am J Respir Crit Care Med. 2009;179:1004-1010.

2. Carter ER, Webb CR, Moffitt DR. Evaluation of heliox in children hospitalized with acute severe asthma. A randomized crossover trial. Chest. 1996;109:1256-1261.

3. Kass JE, Castriotta RJ. Heliox therapy in acute severe asthma. Chest. 1995;107:757-760.

4. Kass JE, Terregino CA. The effect of heliox in acute severe asthma: a randomized controlled trial. Chest. 1999;116:296-300.

5. Kudukis TM, Manthous CA, Schmidt GA, Hall JB, Wylam ME. Inhaled helium-oxygen revisited: effect of inhaled helium-oxygen during the treatment of status asthmaticus in children. $J$ Pediatr. 1997;130:217-224.

6. Manthous CA, Hall JB, Caputo MA, et al. Heliox improves pulsus paradoxus and peak expiratory flow in nonintubated patients with severe asthma. Am J Respir Crit Care Med. 1995;151:310-314.

7. Shiue ST, Gluck EH. The use of helium-oxygen mixtures in the support of patients with status asthmaticus and respiratory acidosis. $J$ Asthma. 1989;26:177-180.

8. Verbeek PR, Chopra A. Heliox does not improve FEV1 in acute asthma patients. J Emerg Med. 1998;16:545-548.

9. Dorfman TA, Shipley ER, Burton JH, Jones P, Mette SA. Inhaled heliox does not benefit ED patients with moderate to severe asthma. Am J Emerg Med. 2000;18:495-497.

10. Henderson SO, Acharya P, Kilaghbian T, Perez J, Korn CS, Chan LS. Use of heliox-driven nebulizer therapy in the treatment of acute asthma. Ann Emerg Med. 1999;33:141-146.

11. Rose JS, Panacek EA, Miller P. Prospective randomized trial of heliox-driven continuous nebulizers in the treatment of asthma in the emergency department. J Emerg Med. 2002;22:133-137.

12. Bateman ED, Hurd SS, Barnes PJ, et al. Global strategy for asthma management and prevention: GINA executive summary. Eur Respir J. 2008;31:143-178.

13. Colebourn CL, Barber V, Young JD. Use of helium-oxygen mixture in adult patients presenting with exacerbations of asthma and chronic obstructive pulmonary disease: a systematic review. Anaesthesia. 2007;62: 34-42.

14. Diehl JL, Peigne V, Guérot E, Faisy C, Lecourt L, Mercat A. Helium in the adult critical care setting. Ann Intensive Care. 2011;1: $1-5$.

15. O’Donnell DE, Banzett RB, Carrieri-Kohlman V, et al. Pathophysiology of dyspnea in chronic obstructive pulmonary disease: a roundtable. Proc Am Thorac Soc. 2007;4:145-168.
16. Sharafkhaneh A, Mattewal AS, Abraham VM, Dronavalli G, Hanania NA. Budesonide/formoterol combination in COPD: a US perspective. Int J Chron Obstruct Pulmon Dis. 2010;5:357-366.

17. Donahoe M, Rogers RM, Wilson DO, Pennock BE. Oxygen consumption of the respiratory muscles in normal and in malnourished patients with chronic obstructive pulmonary disease. Am Rev Respir Dis. 1989; 140:385-391.

18. Katz IM, Martin AR, Muller PA, et al. The ventilation distribution of helium-oxygen mixtures and the role of inertial losses in the presence of heterogeneous airway obstructions. J Biomech. 2011;44:1137-1143.

19. Martin AR, Katz IM, Terzibachi K, Gouinaud L, Caillibotte G, Texereau J. Bench and mathematical modeling of the effects of breathing a helium/oxygen mixture on expiratory time constants in the presence of heterogeneous airway obstructions. Biomed Eng Online. 2012;11:27.

20. Martin AR, Katz IM, Jenofi K, Caillibotte G, Brochard L, Texereau J. Bench experiments comparing simulated inspiratory effort when breathing helium-oxygen mixtures to that during positive pressure support with air. BMC Pulm Med. 2012;12:62.

21. Jaber S, Fodil R, Carlucci A, et al. Noninvasive ventilation with heliumoxygen in acute exacerbations of chronic obstructive pulmonary disease. Am J Respir Crit Care Med. 2000;161:1191-1200.

22. Vogiatzis I. Strategies of muscle training in very severe COPD patients. Eur Respir J. 2011;38:971-975.

23. Eves ND, Petersen SR, Haykowsky MJ, Wong EY, Jones RL. Heliumhyperoxia, exercise, and respiratory mechanics in chronic obstructive pulmonary disease. Am J Respir Crit Care Med. 2006;174:763-771.

24. Palange P, Valli G, Onorati P, et al. Effect of heliox on lung dynamic hyperinflation, dyspnea, and exercise endurance capacity in COPD patients. J Appl Physiol. 2004;97:1637-1642.

25. Pecchiari M, Pelucchi A, D’Angelo E, Foresi A, Milic-Emili J, D'Angelo E. Effect of heliox breathing on dynamic hyperinflation in COPD patients. Chest. 2004;125:2075-2082.

26. Laude EA, Duffy NC, Baveystock C, et al. The effect of helium and oxygen on exercise performance in chronic obstructive pulmonary disease - a randomized crossover trial. Am J Respir Crit Care Med. 2006; 173:865-870.

27. Hess DR. The evidence for noninvasive positive-pressure ventilation in the care of patients in acute respiratory failure: a systematic review of the literature. Respir Care. 2004;49:810-829.

28. Rabe KF, Hurd S, Anzueto A, et al. Global strategy for the diagnosis, management, and prevention of chronic obstructive pulmonary disease: GOLD executive summary. Am J Respir Crit Care Med. 2007; 176:532-555.

29. Quanjer PH, Tammeling GJ, Cotes JE, Pedersen OF, Peslin R, Yernault JC. Official Statement of the European Respiratory Society. Lung volumes and forced ventilatory flows. Report Working Party Standardization of Lung Function Tests, European Community for Steel and Coal. Eur Respir J Suppl. 1993;16:5-40.

30. Diaz O, Villafranca C, Ghezzo H, et al. Role of inspiratory capacity on exercise tolerance in COPD patients with and without tidal expiratory flow limitation at rest. Eur Respir J. 2000;16:269-275.

31. Guenette JA, Sheel AW. Physiological consequences of a high work of breathing during heavy exercise in humans. J Sci Med Sport. 2007;10:341-350.

32. Jetté M, Sidney K, Blümchen G. Metabolic equivalents (METS) in exercise testing, exercise prescription, and evaluation of functional capacity. Clin Cardiol. 1990;13:555-565.

33. Balady GJ, Arena R, Sietsema K, et al. Clinicians guide to cardiopulmonary exercise testing in adults a scientific statement from the American heart association. Circulation. 2010;122:191-225.

34. D'Angelo E, Santus P, Civitillo MF, Centanni S, Pecchiari M. Expiratory flow-limitation and heliox breathing in resting and exercising COPD patients. Respir Physiol Neurobiol. 2009;169:291-296.

35. Montesantos S, Katz I, Fleming J, et al. Airway morphology from high resolution computed tomography in healthy subjects and patients with moderate persistent asthma. Anat Rec. 2013;296:852-866. 
36. Puente-Maestu L, Garcia de Pedro J, Martínez-Abad Y, Ruiz de Oña JM, Llorente D, Cubillo JM. Dyspnea, ventilatory pattern, and changes in dynamic hyperinflation related to the intensity of constant work rate exercise in COPD. Chest J. 2005;128:651-656.
37. Moga AM, de Marchie M, Saey D, Spahija J. Mechanisms of nonpharmacologic adjunct therapies used during exercise in COPD. Respir Med. 2012;106:614-626.

International Journal of COPD

\section{Publish your work in this journal}

The International Journal of COPD is an international, peer-reviewed journal of therapeutics and pharmacology focusing on concise rapid reporting of clinical studies and reviews in COPD. Special focus is given to the pathophysiological processes underlying the disease, intervention programs, patient focused education, and self management protocols.
Dovepress

This journal is indexed on PubMed Central, MedLine and CAS. The manuscript management system is completely online and includes a very quick and fair peer-review system, which is all easy to use. Visit $\mathrm{http}: / / \mathrm{www}$.dovepress.com/testimonials.php to read real quotes from published authors.

Submit your manuscript here: http://www.dovepress.com/international-journal-of-chronic-obstructive-pulmonary-disease-journal 